\title{
Comportamento vegetativo e produtividade de girassol em função do arranjo espacial das plantas ${ }^{1}$
}

\author{
Vegetative behavior and productivity of the sunflower depending on the spatial \\ arrangement of the plants
}

\author{
Francisco Thiago Coelho Bezerra ${ }^{2 *}$, Alek Sandro Dutra ${ }^{3}$, Marlene Alexandrina Ferreira Bezerra ${ }^{4}$, Antônio \\ Francelino de Oliveira Filho ${ }^{5}$ e Geovânio de Lima Barros ${ }^{5}$
}

\begin{abstract}
RESUMO - A cultura do girassol expressiva nos cenários nacional e internacional devido, principalmente, a possibilidade da utilização do óleo na fabricação de biodiesel. O presente trabalho objetivou avaliar os efeitos de arranjos espaciais das plantas sobre as características vegetativas e a produtividade de aquênios de girassol da variedade Embrapa $122 \mathrm{em}$ dois locais de cultivo. Os experimentos foram desenvolvidos na Área Experimental do Departamento de Fitotecnia no Campus do Pici, em Fortaleza-CE, e na Fazenda Experimental Vale do Curu, em Pentecoste-CE. Foram avaliados 16 tratamentos obtidos pelas combinações entre quatro espaçamentos entre linhas $(0,30 ; 0,50 ; 0,70$ e $0,90 \mathrm{~m})$ e quatro densidades de plantio $\left(30.000 ; 45.000 ; 60.000\right.$ e 75.000 plantas ha $\left.^{-1}\right)$ os quais foram distribuídos em quatro blocos casualizados. As características vegetativas consistiram na determinação do diâmetro do caule, comprimento da haste, número de folhas, área foliar e índice de área foliar. Ao final do ciclo da cultura também se determinou a produtividade de aquênio. Os experimentos foram analisados de forma conjunta em relação ao local de cultivo, sendo os dados submetidos à análise de variância $\mathrm{e}$ os fatores quantitativos testados por meio de regressão utilizando o teste $\mathrm{F}(\mathrm{p}<0,05)$ para verificar o ajuste dos modelos. Os fatores estudados não interagem simultaneamente sobre o comportamento vegetativo e produtividade, sendo o local de cultivo preponderante. A competição intraespecífica afeta o comportamento vegetativo do girassol. No manejo espacial da cultura, o espaçamento entre linhas pode afetar a produtividade de aquênios de girassol dependendo do local de cultivo.
\end{abstract}

Palavras-chave: Helianthus annuus. Espaçamento. Densidade.

\begin{abstract}
Cultivation of the sunflower is becoming increasingly more significant both in the domestic and international markets, mainly due to the possibility of using the oil for the production of biodiesel. The objective of the present work was to evaluate the effects of spatial arrangements of the plants on the vegetative characteristics and productivity of achenes in the Embrapa 122 variety of sunflower at two cultivation sites. The experiments were carried out in the Experimental Area of the Department of Plant Science on the Pici Campus in Fortaleza, Ceará, Brazil, and the on the Vale do Curu Experimental Farm at Pentecost, Ceará, Brazil. Sixteen treatments were evaluated made up of combinations of four row spacings $(0.30,0.50,0.70$ and $0 . \mathrm{m})$ and four planting densities $\left.\left(30,000,45,000,60,000 \text { and 75,000 } \text { plants }^{-1}\right)^{-1}\right)$ and divided into four randomised blocks. For the vegetative characteristics, the stalk diameter, stem length, leaf number, leaf area and leaf area index were all determined. At the end of the crop cycle the production of achenes was also evaluated. The experiments were analysed jointly in relation to the cultivation site, the data undergoing variance analysis, and the quantitative factors tested by regression using the F-test $(\mathrm{p}<0.05)$ to check the fit of the models. The factors studied do not interact on vegetative behaviour and productivity at the same time, the cultivation site being predominant. Intraspecific competition affects the vegetative behaviour of the sunflower. For spatial management of the crop, line spacing may affect productivity of sunflower achenes, depending on the cultivation site.
\end{abstract}

Key words: Helianthus annuus. Spacing. Density.

\footnotetext{
*Autor para correspondência

${ }^{1}$ Recebido para publicação em 26/02/2013; aprovado em 17/12/2013

Parte da Dissertação de Mestrado do primeiro autor, apresentado ao Programa de Pós-Graduação em Fitotecnia/Agronomia, DF/CCA/UFC, Fortaleza-CE

${ }^{2}$ Programa de Pós-Graduação em Agronomia/CCA, Universidade Federal da Paraíba, Rodovia PB 079, Km 12, Caixa Postal 66, Areia-PB, Brasil, 58.397-000,bezerra_ftc@yahoo.com.br

${ }^{3}$ Departamento de Fitotecnia/CCA, Universidade Federal do Ceará, Campus do Pici, Fortaleza-CE, Brasil, alekdutra@ufc.br ${ }^{4}$ Programa de Pós-Graduação em Ciência do Solo/CCA, Universidade Federal da Paraíba, Areia-PB, Brasil, marlene_agro@hotmail.com

${ }^{5}$ Programa de Pós-Graduação em Agronomia/Fitotecnia, Universidade Federal do Ceará, Campus do Pici, Fortaleza-CE, Brasil, agro-engeheiro@ hotmail.com,geovanio_05@yahoo.com.br
} 


\section{INTRODUÇÃO}

O girassol (Helianthus annuus L.) foi introduzido no Brasil no final do século XIX pelos colonos europeus (RIBEIRO, 2008) e se adapta a diferentes condições edafoclimáticas, podendo ser cultivado desde o Rio Grande do Sul até Roraima (LEITE et al., 2007). Essa cultura vem tornando-se expressiva no cenário nacional, devido à qualidade do óleo comestível extraída dos aquênios, ao aproveitamento dos subprodutos em rações para animais, ser alternativa econômica aos sistemas de cultivo (BACKES et al. 2008; PORTO; CARVALHO; PINTO, 2007) e, principalmente, à possibilidade da utilização do óleo na fabricação de biodiesel (YOKOMIZO, 2003).

Por estas razões vem se observando um aumento nas produções nacional e internacional de grãos e óleos de girassol (MAPA, 2011). Entre as safras de 1998/1999 e 2008/2009 houve aumento de $14,8 \%$ na produção de grãos, passando de 26,63 para 32,3 milhões de toneladas (MAPA, 2011). Na safra brasileira de 2011/2012 a área plantada e a produção alcançaram 74.500 ha e 116.400 toneladas, respectivamente, com produtividade média de $1.563 \mathrm{~kg} \mathrm{ha}^{-1}$ (CONAB, 2013).

Diversos fatores afetam o desempenho de girassol de elevado potencial produtivo estando diretamente mais relacionado, de acordo com Leite et al. (2007), à época de semeadura, o genótipo, o manejo adequado da fertilidade do solo e os fatores ambientais, como a distribuição de água uniforme durante o ciclo da cultura. A produtividade da cultura está diretamente relacionada com a disponibilidade de água. Estudando o desempenho produtivo de girassol Afférri et al. (2008) obtiveram interação entre genótipo e o local de cultivo, marcada por variações significativas no rendimento. Podendo o local de cultivo ser determinante na produtividade como observado por Broch et al. (2009), que observaram variações de produtividade entre genótipos de girassol e obtiveram diferenças em relação ao local de cultivo.

O arranjo espacial das plantas também é um fator de elevada importância, pois pode afetar as características produtivas e a produtividade de muitas culturas. Plantas submetidas a condições de sombreamento, devido ao aumento da densidade, podem alocar recursos para um rápido crescimento em extensão (TAIZ; ZEIGER, 2009). Essa modificação no crescimento é resultante da manifestação da plasticidade fenotípica às condições do habitat (LARCHER, 2006), por isso, o estudo das características produtivas se faz necessário para que haja melhores interpretações das respostas adaptativas das plantas e consequentemente um melhor planejamento. De acordo com Pivetta et al. (2012), a relação entre os componentes de produção acarretaram em uma resposta em produtividade.
De modo geral, o estudo do arranjo permite definir a melhor configuração das plantas, de maneira a reduzir a competição por recursos ambientais além de, buscar maior eficiência no controle de plantas daninhas e adequação ao maquinário disponível. Estudando arranjos espaciais, Silva e Nepomuceno (1991), concluíram que para cultivar de girassol precoce e de porte baixo, o melhor rendimento é obtido em densidades superiores à recomendada para cultivar tardia. Já Martin et al. (2012), não obtiveram diferenças na produtividade de genótipos de girassol cultivadas nos espaçamentos entre linhas de 0,4 e $0,8 \mathrm{~m}$, sob a densidade de 55.000 plantas ha $^{-1}$.

Diante do exposto, o presente trabalho objetivou avaliar os efeitos de arranjos espaciais das plantas sobre as características vegetativas e a produtividade de aquênios de girassol da variedade Embrapa 122 em dois locais de cultivo.

\section{MATERIAL E MÉTODOS}

O trabalho foi desenvolvido na Área Experimental do Departamento de Fitotecnia (AEDF), no Campus do Pici ( $3^{\circ} 44^{\prime}$ de latitude Sul, $38^{\circ} 33^{\prime}$ a oeste de Greenwich e $19,5 \mathrm{~m}$ de altitude), em Fortaleza-CE, e na Fazenda Experimental Vale do Curu (FEVC) ( $3^{\circ} 47^{\prime}$ de latitude Sul, 39 $16^{\prime}$ a oeste de Greenwich e $45 \mathrm{~m}$ de altitude), em Pentecoste-CE.

De acordo com a classificação da Embrapa (2006), os solos utilizados na condução dos experimentos são do tipo Argissolo Vermelho Amarelo para a AEDF, em Fortaleza, e Planossolo para a FEVC, em Pentecoste. Previamente ao preparo das áreas experimentais, que consistiu em aração e gradagem, retiraram-se amostras nas camadas de 0-20 e 20-40 cm de profundidade do perfil com o objetivo de caracterizá-las quanto às propriedade físico-químicas, as quais podem ser observadas na Tabela 1.

Quanto à classificação climática, conforme Köppen, o município de Fortaleza está inserido no tipo Aw', tratando-se de um clima tropical chuvoso, enquanto que em Pentecoste predomina o tipo BSw'h', ou seja, grupo de clima semiárido seco com uma pequena temporada úmida. Os dados meteorológicos diários da temperatura média do ar e da precipitação pluviométrica acumulada nas áreas experimentais durante a condução dos experimentos encontram-se na Figura 1.

A adubação consistiu na aplicação de ureia (45\% de nitrogênio), superfosfato simples $\left(20 \%\right.$ de $\left.\mathrm{P}_{2} \mathrm{O}_{5}\right)$ e cloreto de potássio $\left(60 \%\right.$ de $\mathrm{K}_{2} \mathrm{O}$ ) na recomendação de 50:50:40 kg ha-1, correspondentes ao $\mathrm{N}$, ao $\mathrm{P}_{2} \mathrm{O}_{5}$ e ao $\mathrm{K}_{2} \mathrm{O}$, respectivamente. A adubação com fósforo e potássio foi realizada em fundação. Já o nitrogênio foi aplicado de forma parcelada, sendo um terço na 
Tabela 1 - Resultados das análises físico-químicas na Área Experimental do Departamento de Fitotecnia ( $\downarrow$ ), em Fortaleza, e na Fazenda Experimental Vale do Curu (๘), em Pentecoste, nas camadas de 0-20 (1) e 20-40 (2) cm de profundidade do perfil previamente a instalação do experimento, 2012

\begin{tabular}{|c|c|c|c|c|c|c|c|c|c|c|c|c|c|c|}
\hline \multirow{3}{*}{ Área } & \multicolumn{14}{|c|}{ Atributos Químicos } \\
\hline & $\mathrm{pH}$ & $\mathrm{CE}$ & $\mathrm{Ca}^{2+}$ & $\mathrm{Mg}^{2+}$ & $\mathrm{K}^{+}$ & $\mathrm{Al}^{3+}$ & $\mathrm{Na}^{+}$ & $\mathrm{H}^{+}+\mathrm{Al}^{3+}$ & SB & CTC & $\mathrm{P}^{5+}$ & $\mathrm{m}$ & $\mathrm{V}$ & M.O. \\
\hline & $\left(1: 2,5 \mathrm{H}_{2} \mathrm{O}\right)$ & $\mathrm{dS} \mathrm{m}^{-1}$ & \multicolumn{8}{|c|}{$\mathrm{cmol}_{\mathrm{c}} \mathrm{kg}^{-1}$} & $\mathrm{mg} \mathrm{kg}^{-1}$ & \multicolumn{3}{|c|}{$\%$} \\
\hline$\bullet-1$ & 6,4 & 0,11 & 0,90 & 1,00 & 0,09 & 0,05 & 0,05 & 0,33 & 2,04 & 2,37 & 4 & 2 & 83 & 0,64 \\
\hline$\bullet-2$ & 6,3 & 0,11 & 1,10 & 0,60 & 0,08 & 0,05 & 0,06 & 0,17 & 1,84 & 0,23 & 5 & 3 & 90 & 0,63 \\
\hline$\square-1$ & 5,2 & 0,17 & 0,80 & 1,40 & 0,13 & 0,35 & 0,04 & 0,99 & 2,37 & 3,36 & 4 & 13 & 71 & 0,76 \\
\hline $\mathbf{m}-2$ & 5,1 & 0,10 & 0,50 & 1,10 & 0,09 & 0,50 & 0,02 & 1,16 & 1,71 & 2,87 & 3 & 23 & 59 & 0,38 \\
\hline \multirow{3}{*}{ Área } & \multicolumn{14}{|c|}{ Atributos Físicos } \\
\hline & Areia Grossa & Areia Fina & Silte & \multicolumn{2}{|c|}{ Argila } & Argil & Natural & \multicolumn{2}{|c|}{ Densidade do solo } & Densi & le da partícula & \multirow{2}{*}{\multicolumn{3}{|c|}{ Classe textural }} \\
\hline & \multicolumn{5}{|c|}{$\mathrm{g} \mathrm{kg}^{-1}$} & & & \multicolumn{4}{|c|}{$\mathrm{g} \mathrm{cm}^{-3}$} & & & \\
\hline$\bullet-1$ & 248 & 607 & 74 & \multicolumn{2}{|c|}{71} & \multicolumn{2}{|c|}{34} & \multicolumn{2}{|c|}{1,36} & \multicolumn{2}{|r|}{2,61} & \multicolumn{3}{|c|}{ Areia Franca } \\
\hline$\bullet-2$ & 388 & 431 & 89 & \multicolumn{2}{|c|}{92} & \multicolumn{2}{|c|}{64} & \multicolumn{2}{|c|}{1,39} & \multicolumn{2}{|c|}{2,61} & \multicolumn{3}{|c|}{ Areia Franca } \\
\hline $\mathbf{- 1}-1$ & 363 & 477 & 114 & \multicolumn{2}{|c|}{46} & \multicolumn{2}{|c|}{22} & \multicolumn{2}{|c|}{1,58} & \multicolumn{2}{|c|}{2,65} & \multicolumn{3}{|c|}{ Areia Franca } \\
\hline $\mathbf{m}-2$ & 420 & 486 & 51 & 4 & & & 14 & 1, & & & 2,68 & \multicolumn{3}{|c|}{ Areia } \\
\hline
\end{tabular}

Fonte: Laboratório de análise de solo e planta do Departamento de Solos e Nutrição de Plantas da Universidade Federal do Ceará, Fortaleza - CE

Figura 1 - Dados meteorológicos de temperatura média do ar (-) e precipitação pluviométrica acumulada (----) no Campus do Pici (o), em Fortaleza, e na Fazenda Experimental Vale do Curu (•), em Pentecoste, no ano de 2012

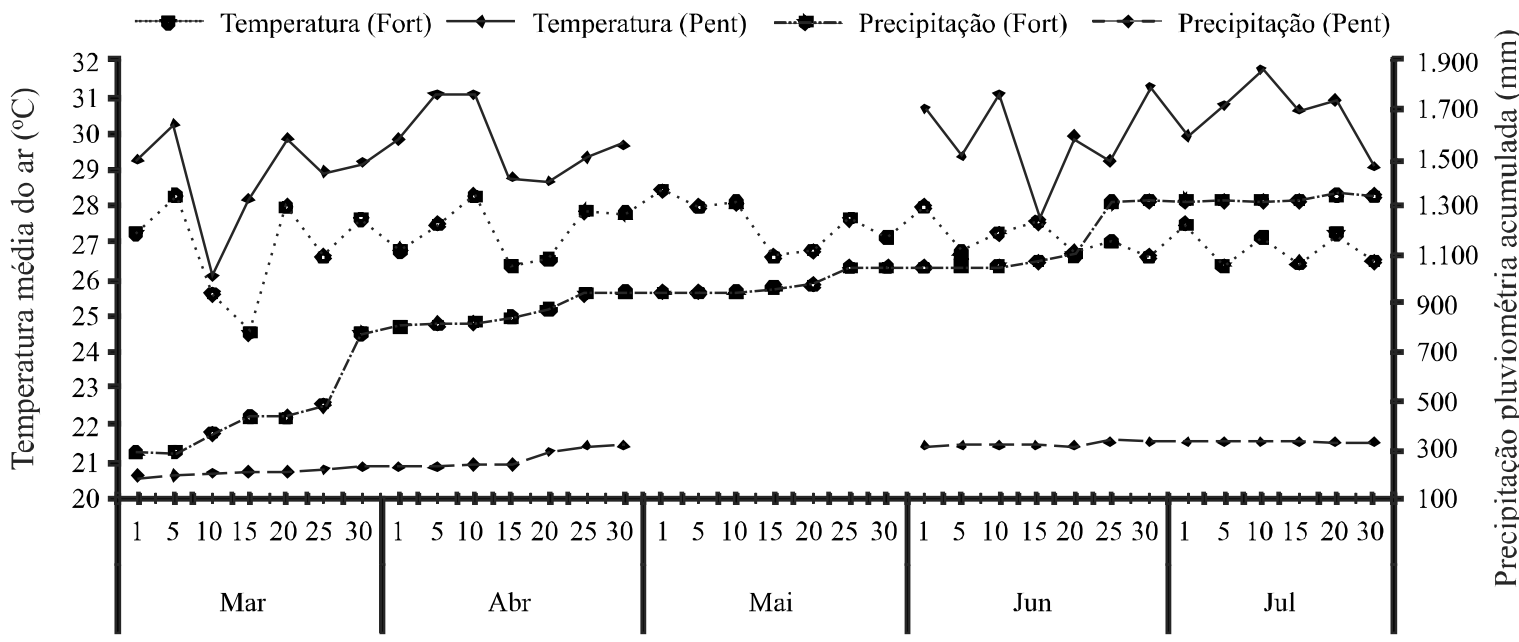

Fonte: Departamento de Engenharia Agrícola da Universidade Federal do Ceará, Fortaleza-CE

adubação de fundação e o restante em cobertura aos 35 dias após a semeadura juntamente com a adubação na dose de $2 \mathrm{~kg} \mathrm{ha}^{-1}$ de boro, tendo como fonte o ácido bórico $(17 \% \mathrm{~B})$.

A semeadura foi realizada de forma manual sendo que na FEVC, em Pentecoste, foi realizada em 15 de março de 2012 e o trabalho foi conduzido em sequeiro, enquanto que, na AEDF, em Fortaleza, a semeadura ocorreu em 15 de abril de 2012 e utilizou-se de irrigações suplementares. As plantas daninhas foram controladas através de capinas manuais.

Para se avaliar o arranjo espacial entre as plantas utilizou-se a variedade de girassol Embrapa 122 de ciclo precoce, porte baixo, alta produtividade, tolerante à seca (AMORIM et al., 2008) e com teor de óleo variando de 40 a 45\% (RIBEIRO, 2008). Os tratamentos foram compostos pelas combinações entre quatro espaçamentos entre linhas $(0,30 ; 0,50 ; 0,70$ e $0,90 \mathrm{~m})$ e quatro densidades de plantio 
(30.000; 45.000; 60.000 e 75.000 plantas ha $\mathrm{ha}^{-1}$ ), totalizando 16 tratamentos que foram distribuídos em quatro blocos casualizados e a unidade experimental constituída por uma parcela de 6 metros de comprimento e quatro linhas distanciadas conforme o espaçamento entre plantas, sendo a área útil às duas linhas centrais excluindo-se as plantas das extremidades dessas linhas.

Em cada parcela foram marcadas quatro plantas nas quais se avaliaram aos 42 e aos 70 dias após a semeadura o diâmetro do caule ao nível do solo (DNS), com o auxílio de paquímetro digital e o comprimento da haste $(\mathrm{CH})$, com uma trena milimetrada. Também se avaliaram aos 42 dias após a semeadura o número de folhas (NF), considerando folhas somente aquelas que estavam expandidas e com no mínimo de $50 \%$ do limbo foliar, a área foliar (AF), conforme metodologia descrita por Ashley, Doss e Vennett (1963) e descrita a seguir na equação 1:

$A F=C x \operatorname{Lx} N \times f$

sendo: $\mathrm{AF}=$ área foliar, $\mathrm{cm}^{2}$ planta $^{-1} ; \mathrm{C}=$ comprimento médio das folhas, $\mathrm{cm}$ (média de cinco folhas); $\mathrm{L}=$ maior largura da folha, $\mathrm{cm}$ (média de cinco folhas); $\mathrm{N}=$ número de folhas por planta, $\mathrm{n}^{\circ}$ e $\mathrm{f}=$ fator de correção $-0,5852$ (AQUINO et al., 2011).

O índice de área foliar (IAF) foi determinado através da relação entre a área foliar da planta pela área que a mesma ocupava no terreno. A colheita foi realizada aos 98 dias após a semeadura e o beneficiamento dos aquênios realizado de forma manual, sendo a produtividade corrigida para $12 \%$ de umidade.

Os resultados de cada área experimental foram submetidos à análise de variância sendo, em seguida, avaliados quanto à homogeneidade dos erros através da relação entre o maior e o menor erro. Estabelecida a homogeneidade dos erros procedeu-se a análise conjunta por meio da análise de variância e de regressão polinomial, utilizando-se o teste $\mathrm{F}(\mathrm{p}<0,05)$ para se verificar a significância dos fatores, como também de suas interações e dos ajustes dos dados às equações de regressão.

\section{RESULTADOS E DISCUSSÃO}

Na Tabela 2 observa-se o resumo das análises de variância das características vegetativas, diâmetro do caule ao nível do solo, comprimento da haste, número de folhas, área foliar e índice de área foliar e a produtividade em aquênios de plantas de girassol da variedade Embrapa 122 cultivadas em função do espaçamento entre linhas e em função da densidade de plantio na Área Experimental do Departamento de Fitotecnia (AEDF), em Fortaleza, e na Fazenda Experimental Vale do Curu (FEVC), em Pentecoste.

Para o diâmetro do caule ao nível do solo, independentemente da época de avaliação, as interações entre os fatores estudados foram não significativas (Tabela 2). Aos 42 dias após a semeadura o espaçamento entre linhas, a densidade de plantio e o local de cultivo, isoladamente, afetaram significativamente esta variável. Em relação ao local de cultivo, os diâmetros foram, em média, de 12,33 e 13,02 mm por planta quando o cultivo foi realizado na AEDF, em Fortaleza, e na FEVC, em Pentecoste, respectivamente. Já aos 70 dias após a semeadura apenas o fator densidade de plantio impôs diferenças significativas e a média foi de 12,93 mm. As análises desses dados em função do espaçamento entre linhas e em função da densidade de plantio podem ser observadas na Figura 2.

Os dados de crescimento do caule em diâmetro ao nível do solo aos 42 dias após a semeadura em função do espaçamento entre linhas na AEDF, em Fortaleza, não se ajustaram aos modelos de regressão testados sendo apresentado em termos médios (Figura 2A). Já na FEVC, em Pentecoste, estima-se um crescimento de $0,33 \mathrm{~mm}$ por planta para cada aumento de $0,1 \mathrm{~m}$ entre linhas (Figura 2A). Na avaliação realizada aos 70 dias após a semeadura, independentemente do local de cultivo, estima-se um crescimento de $0,18 \mathrm{~mm}$ por planta para cada acréscimo de $0,1 \mathrm{~m}$ no espaçamento (Figura 2C). Já em função da densidade de plantio nas avaliações realizadas aos 42 e aos 70 dias após a semeadura estima-se que os diâmetros do caule ao nível do solo das plantas decresçam linearmente (Figuras 2B e D, respectivamente), independentemente do local de cultivo.

Observou-se que a maior competição intraespecífica, resultante tanto de um menor espaçamento entre linhas como de uma maior densidade de plantio, diminui o diâmetro do caule ao nível do solo. Essa modificação no crescimento pode ser resultante da manifestação da plasticidade fenotípica às condições do habitat (LARCHER, 2006). Avaliando genótipos de girassol cultivados na população de 42.000 planta ha-1, Amorim et al. (2008), obtiveram para a variedade Embrapa 122 o diâmetro médio de $18 \mathrm{~mm}$, enquanto que, Backes et al. (2008), em um arranjo de 40.000 plantas ha ${ }^{-1}$ obtiveram 22,03 e 25,61 mm nos experimentos semeados em janeiro e fevereiro de 2007 no município de Papanduva-SC, respectivamente, não diferindo dos outros genótipos em cada ensaio. Já Braz e Rossetto (2009a), avaliando o desempenho de girassol em resposta ao vigor dos aquênios obtiveram 19,11 e 25,54 mm de diâmetro do caule nas avaliações realizadas aos 40 e aos 80 dias após a semeadura. 
Tabela 2 - Resumo das análises de variância das variáveis: diâmetro do caule ao nível do solo aos 42 dias e aos 70 dias após a semeadura (DSN1 e DNS2, respectivamente), comprimento da haste aos 42 dias e aos 70 dias após a semeadura (CH1 e CH2, respectivamente) e número de folhas (NF), área foliar (AF) e índice de área foliar (IAF) aos 42 dias após a semeadura e produtividade de aquênios (PROD) de girassol da variedade Embrapa 122 em função do arranjo espacial das plantas e do local de cultivo, 2012

\begin{tabular}{|c|c|c|c|c|c|}
\hline \multirow{2}{*}{ Fonte de Variação } & \multirow{2}{*}{ GL } & \multicolumn{4}{|c|}{ Quadrado Médio } \\
\hline & & DNS1 & DNS2 & $\mathrm{CH} 1$ & $\mathrm{CH} 2$ \\
\hline Bloco (local) & 6 & 7,094 & 19,699 & $1.099,001$ & $1.141,250$ \\
\hline Espaçamento (E) & 3 & $10,546^{* *}$ & $7,326^{\mathrm{ns}}$ & $1.764,428^{\mathrm{ns}}$ & $500,151^{*}$ \\
\hline Densidade (D) & 3 & $26,016^{* *}$ & $50,715^{* *}$ & $561,101^{\mathrm{ns}}$ & $256,113^{\mathrm{ns}}$ \\
\hline$E \times D$ & 9 & $2,524^{\mathrm{ns}}$ & $5,378^{\mathrm{ns}}$ & $573,324^{\mathrm{ns}}$ & $115,941^{\mathrm{ns}}$ \\
\hline Local (L) & 1 & $13,626^{*}$ & $11,205^{\mathrm{ns}}$ & $14.061,009 * *$ & $2.400,637 * *$ \\
\hline $\mathrm{L} \times \mathrm{E}$ & 3 & $4,959^{\mathrm{ns}}$ & $3,255^{\mathrm{ns}}$ & $1.033,642^{\mathrm{ns}}$ & $417,049^{\mathrm{ns}}$ \\
\hline$L \times D$ & 3 & $1,104^{\mathrm{ns}}$ & $3,272^{\mathrm{ns}}$ & $1.484,655^{\mathrm{ns}}$ & $235,762^{\mathrm{ns}}$ \\
\hline$L \times E \times D$ & 9 & $1,608^{\mathrm{ns}}$ & $0,750^{\mathrm{ns}}$ & $928,419^{\mathrm{ns}}$ & $75,999^{\mathrm{ns}}$ \\
\hline Erro & 87 & 2,595 & 2,924 & 762,404 & 155,860 \\
\hline Média & & $12,68 \mathrm{~mm}$ planta $^{-1}$ & $12,93 \mathrm{~mm}_{\text {planta }}{ }^{-1}$ & $81,2 \mathrm{~cm}$ planta $^{-1}$ & $117,0 \mathrm{~cm}$ planta $^{-1}$ \\
\hline $\mathrm{CV}(\%)$ & & 12,70 & 13,23 & 34,01 & 10,67 \\
\hline \multirow{2}{*}{ Fonte de Variação } & \multirow{2}{*}{ GL } & \multicolumn{2}{|c|}{ Quadrado Médio } & & \\
\hline & & $\mathrm{NF}$ & $\mathrm{AF}$ & IAF & PROD \\
\hline Bloco (local) & 6 & 4,320 & $987.457,49$ & 0,191 & $482.581,69$ \\
\hline Espaçamento (E) & 3 & $9,533 *$ & $1.104 .331,24 *$ & $0,218^{*}$ & $213.951,71^{\mathrm{ns}}$ \\
\hline Densidade (D) & 3 & $6,559^{\text {ns }}$ & $5.053 .780,45^{* *}$ & $3,068 * *$ & $27.981,31^{\mathrm{ns}}$ \\
\hline$E \times D$ & 9 & $1,111^{\mathrm{ns}}$ & $299.994,82^{\mathrm{ns}}$ & $0,058^{\mathrm{ns}}$ & $72.648,58^{\mathrm{ns}}$ \\
\hline Local (L) & 1 & $109,543 * *$ & $1.543 .391,05^{*}$ & $0,462 *$ & $20.239 .657,67 * *$ \\
\hline $\mathrm{LxE}$ & 3 & $3,969^{\text {ns }}$ & $516.971,08^{\mathrm{ns}}$ & $0,102^{\mathrm{ns}}$ & $324.509,09 *$ \\
\hline$L \times D$ & 3 & $7,450^{\text {ns }}$ & $180.233,34^{\mathrm{ns}}$ & $0,121^{\mathrm{ns}}$ & $230.583,31^{\mathrm{ns}}$ \\
\hline$L \times E \times D$ & 9 & $3,054^{\mathrm{ns}}$ & $286.887,76^{\mathrm{ns}}$ & $0,072^{\mathrm{ns}}$ & $32.726,93^{\mathrm{ns}}$ \\
\hline Erro & 87 & 3,323 & $353.109,07$ & 0,077 & $94.553,040$ \\
\hline Média & & 21,4 folhas planta $^{-1}$ & $2.452,28 \mathrm{~cm}^{2}$ planta $^{-1}$ & $0,077 \mathrm{~m}^{2} \mathrm{~m}^{-2}$ planta $^{-1}$ & $1.099,84 \mathrm{~kg} \mathrm{ha}^{-1}$ \\
\hline $\mathrm{CV}(\%)$ & & 8,51 & 24,23 & 22,69 & 27,96 \\
\hline
\end{tabular}

ns, * e **: não significativo e significativo a 1 e $5 \%$, respectivamente, pelo teste de $\mathrm{F}$

As interações entre os fatores estudados foram não significativas nas avaliações do comprimento da haste de girassol da variedade Embrapa 122 e, isoladamente apenas o local de cultivo afetou esta variável nas duas épocas avaliadas e o espaçamento entre plantas na avaliação realizada aos 70 dias após a semeadura (Tabela 2). Na AEDF, em Fortaleza, o comprimento médio da haste aos 42 dias após a semeadura foi de $92,5 \mathrm{~cm}$, sendo superior aos $70,4 \mathrm{~cm}$, obtido na FEVC, em Pentecoste. Essa diferença se corrobora aos 70 dias, com as respectivas médias 121,4 e $112,9 \mathrm{~cm}$. As análises desses dados em função do espaçamento entre linhas e em função da densidade de plantio não se ajustaram aos modelos de regressão.
Uma das estratégias utilizadas por plantas classificadas como de sol é a alocação de recursos para um rápido crescimento em extensão, quando submetidas a condições de sombreamento (TAIZ; ZEIGER, 2009). E, como pode-se observar, o comprimento da haste das plantas de girassol não sofreu efeito dos arranjos espaciais (Tabela 2), podendo a diferenças do crescimento está mais relacionada à precipitação pluviométrica (Figura 1), pois a radiação e a temperatura só prejudicam a cultura com valores muito altos (ZAFFARONI; SILVA; AZEVEDO, 1994).

Segundo Arnabli, Guimarães e Farias Neto (2003), a variedade de girassol Embrapa 122 possue 
Figura 2 - Diâmetro do caule ao nível do solo de plantas de girassol da variedade Embrapa 122 em função do espaçamento entre linhas e em função da densidade de plantio aos 42 (A e B, respectivamente) e aos 70 (C e D, respectivamente) dias após a semeadura na Área Experimental do Departamento de Fitotecnia, em Fortaleza ( ), na Fazenda Experimental Vale do Curu, em Pentecoste (ロ), e média das duas áreas (•), 2012

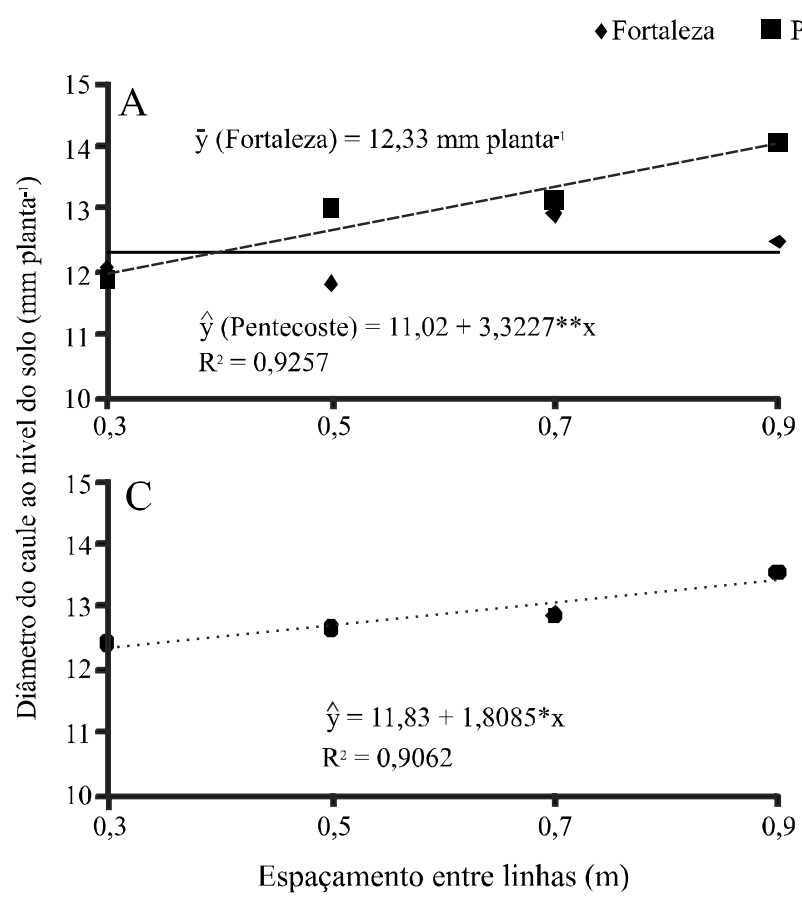

Pentecoste Média
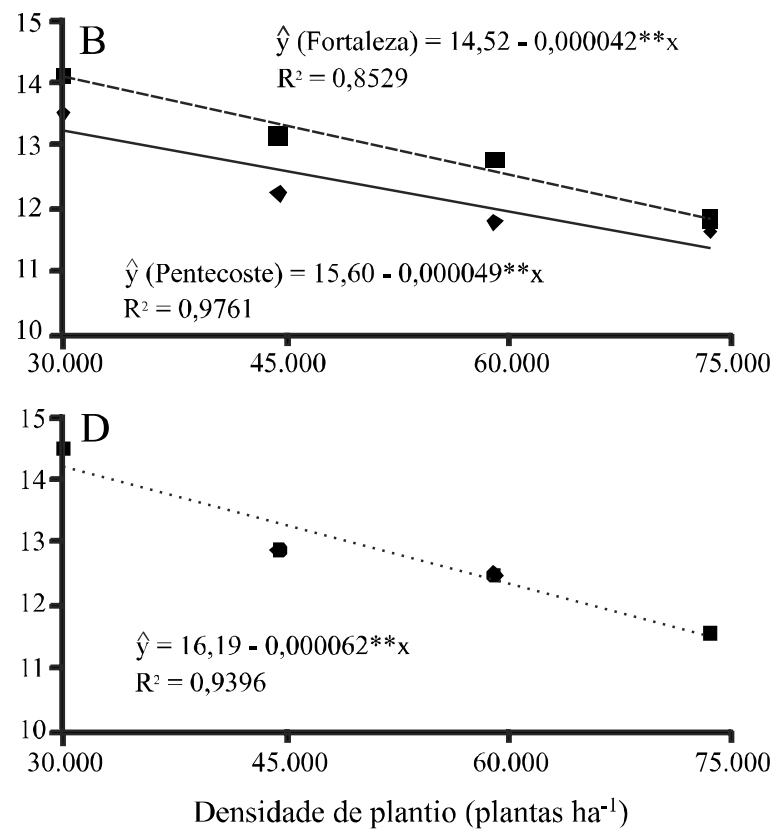

uma menor altura quando comparada com os outros genótipos avaliados, no entanto possui crescimento inicial superior. Para esses mesmos autores o crescimento em altura dessa variedade é limitada quando a saturação por bases ultrapassa $57 \%$. Dessa forma, a baixa precipitação pluviométrica (Figura 1) e a elevada saturação por base (Tabela 1) podem ter comprometido o crescimento das plantas. Nos trabalhos de Backes et al. (2008) e Braz e Rossetto (2009a), a altura das plantas foram respectivamente de 178 e $170 \mathrm{~cm}$, superiores aos evidenciados nesta pesquisa.

O número de folhas em plantas de girassol da variedade Embrapa 122 aos 42 dias após a semeadura foi afetado apenas pelos fatores, local de cultivo e espaçamento entre linhas, de forma isolada, e todas as interações estudadas foram não significativas (Tabela 2). A maior média obteve-se na AEDF, em Fortaleza, sendo de 22,4 folhas por planta, enquanto que, na FEVC, em Pentecoste, o número médio de folhas por plantas foi de 20,5. Esses dados em função do espaçamento entre linhas não se ajustaram aos modelos de regressão testados. Já em função da densidade de plantio obteve-se modelo significativo apenas para uma das áreas de cultivo (Figura 3 ).

Figura 3 - Número de folhas em plantas de girassol da variedade Embrapa 122 aos 42 dias após a semeadura em função da densidade de plantio na Área Experimental do Departamento de Fitotecnia, em Fortaleza ( ), e na Fazenda Experimental Vale do Curu, em Pentecoste (匹), 2012

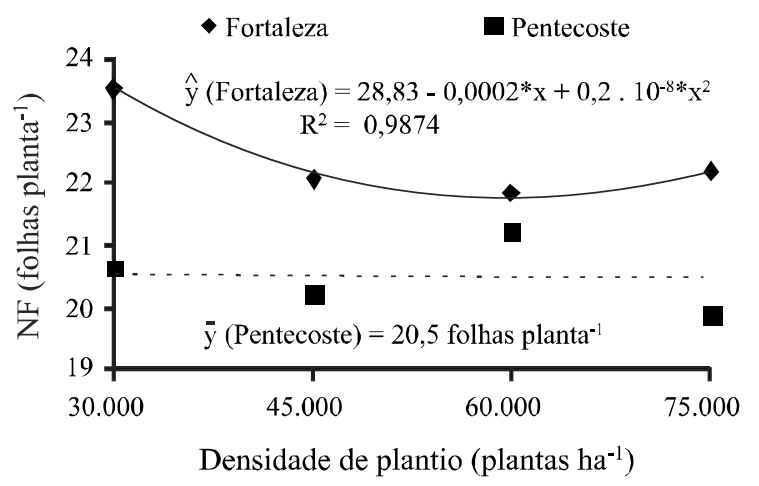

Na AEDF, em Fortaleza, estima-se uma redução de $17 \%$ no número de folhas por planta com o aumento da população de 30.000 para 50.000 plantas ha $^{-1}$ (Figura 3). Já na FEVC, em Pentecoste, a produção 
de folhas não se ajustou aos modelos de regressão testados, tendo-se, em média, 20,5 folhas por planta. As folhas exercem importantes funções, destacando-se por ser um dos principais órgãos pelos quais as plantas normalmente competem pela luz solar, absorvendo-a e influenciando as taxas fotossintéticas e o crescimento (TAIZ; ZEIGER, 2009).

Avaliando cultivares de girassol no município de Gurupi-TO, Afférri et al. (2008), observaram que a época de semeadura foi determinante, encontrando o maior número de folhas por planta quando a semeadura foi realizada no início do mês de janeiro de 2006 (24,6 folhas) e o menor no final do mês de novembro de 2005 (20,5 folhas). Já Amorim et al. (2008), avaliando apenas cultivares obtiveram para a Embrapa 122, em média, 28 folhas por planta, enquanto que, Braz e Rossetto (2009a), encontraram para esta mesma variedade médias de 25,35 e 11,93 folhas por planta aos 40 e 80 dias após a semeadura, respectivamente.

Para a área foliar e para o índice de área foliar, avaliados aos 42 dias após a semeadura em girassol da variedade Embrapa 122, não foram observados interações para o espaçamento entre linhas, a densidade de plantio e o locais de cultivo, porém, isoladamente estes fatores afetaram ambas variáveis (Tabela 2). As plantas cultivadas na AEDF, em Fortaleza, possuíam, em média, 2.561,63 $\mathrm{cm}^{2}$ planta ${ }^{-1}$ e $1,29 \mathrm{~m}^{2} \mathrm{~m}^{-2}$ planta $^{-1}$ de área foliar e de índice de área foliar, respectivamente, sendo superiores às médias obtidas na FEVC, em Pentecoste, que foram de $2.348,05 \mathrm{~cm}^{2}$ planta $^{-1}$ para a área foliar e de $1,17 \mathrm{~m}^{2} \mathrm{~m}^{-2}$ planta $^{-1}$ para o índice de área foliar. As análises em função do espaçamento entre linhas e em função da densidade de plantio podem ser observadas na Figura 4.

Aárea foliar em função do espaçamento entre linhas não se ajustou aos modelos de regressão testados quando cultivadas na AEDF, em Fortaleza, sendo apresentada em termos médios (Figura 4A). Já na FEVC, em Pentecoste, estima-se que ocorra um acréscimo em área foliar na taxa de $104,13 \mathrm{~cm}^{2}$ planta $^{-1}$ para cada acréscimo de $0,1 \mathrm{~m}$ no espaçamento. Para a densidade de plantio, observou-se que a área foliar das plantas cultivadas na AEDF, em Fortaleza, decresce até uma população estimada de 66.429 plantas ha $^{-1}$, enquanto que, na FEVC, em Pentecoste, esse decréscimo é constante, estimado em $0,0195 \mathrm{~cm}^{2}$ por planta para cada

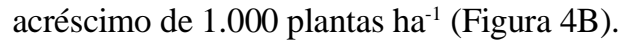

De acordo com Ribeiro (2008), plantas de girassol geralmente possuem de 20 a 40 folhas com área foliar total de $0,9 \mathrm{~m}^{2}$ quando cultivadas em solos profundos e sem deficiência hídrica ou nutricional. Valor este superior

Figura 4 - Área foliar (A e B) e índice de área foliar (C e D) em plantas de girassol variedade Embrapa 122 aos 42 dias após a semeadura em função do espaçamento entre plantas e em função da densidade de plantio na Área Experimental do Departamento de Fitotecnia, em Fortaleza ( ), e na Fazenda Experimental Vale do Curu, em Pentecoste (๘), 2012
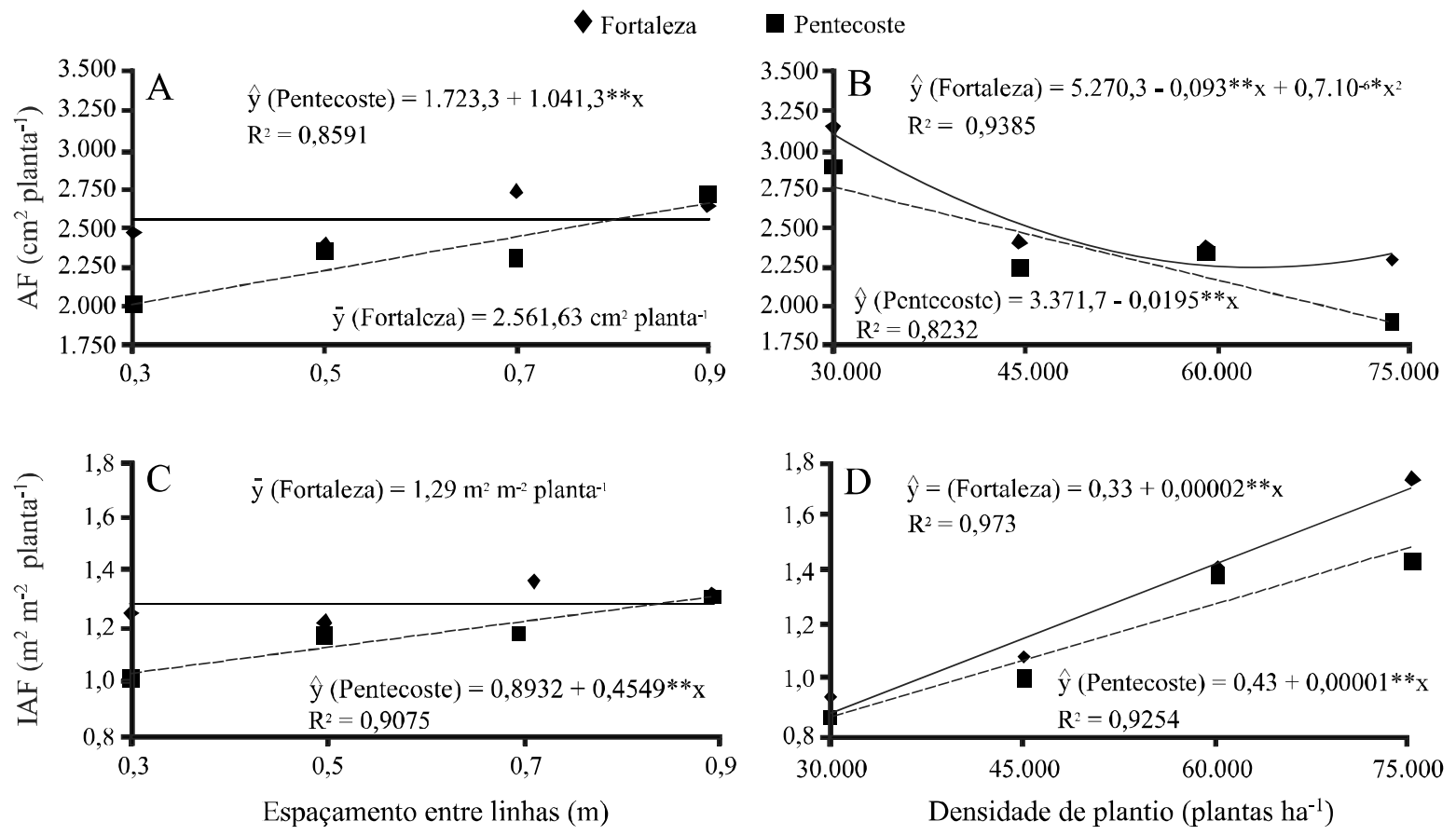
aos supracitados para a variedade Embrapa 122 que, em média, foi de $0,25 \mathrm{~m}^{2}$ (Tabela 2 ), sendo que a diminuição da área foliar é considerada uma resposta precoce ao déficit hídrico (TAIZ; ZEIGER, 2009).

O índice de área foliar em função do espaçamento entre linhas seguiu o mesmo comportamento observado para a área foliar onde, na AEDF, em Fortaleza, os dados não se ajustaram aos modelos de regressão, enquanto que, na FEVC, em Pentecoste, estima-se um acréscimo linear na taxa de $0,045 \mathrm{~m}^{2} \mathrm{~m}^{-2}$ planta $^{-1}$ para cada acréscimo de $0,1 \mathrm{~m}$ no espaçamento entre linhas (Figura 4C). Quanto à densidade de plantio, observouse que à medida que houve aumento na densidade populacional ocorreram acréscimos nos índices de área foliar, estimados em 0,2 e $0,1 \mathrm{~cm}^{2} \mathrm{~cm}^{-2}$ planta $^{-1}$ para cada acréscimo de 1.000 plantas ha ${ }^{-1}$ quando o cultivo foi realizado na AEDF, em Fortaleza, e na FEVC, em Pentecoste, respectivamente (Figura 4D).

De acordo com Larcher (2006), um aumento na taxa de produção pode ser obtido aumentando-se o índice de área foliar que reflete a densidade das folhas, pois há uma maior disponibilidade de superfície fotossinteticamente ativa. Braz e Rossetto (2009b) obtiveram maior índice de área foliar aos 60 dias após a semeadura ocorrendo também diferenças significativas em função da população, sendo o maior índice obtido na densidade de 45.000 plantas ha $^{-1}$

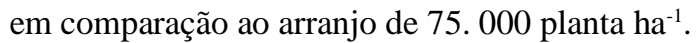

A produtividade de aquênios foi afetada apenas pelo local de cultivo, como também a única interação significativa foi obtida entre o local de cultivo e o espaçamento entre linhas (Tabela 2). Sendo a maior produtividade média de aquênios na AEDF, em Fortaleza, com $1.516,57 \mathrm{~kg} \mathrm{ha}^{-1}$ a qual foi superior à obtida na FEVC, em Pentecoste, que foi de 702,64 $\mathrm{kg} \mathrm{ha}^{-1}$. Já em relação aos modelos de regressão testados para as análises em função do espaçamento entre linhas e em função da densidade de plantio os ajustes foram não significativos, o que dificulta uma melhor interpretação das informações.

Entre os fatores estudados pode-se observar que o local de cultivo foi determinante na produtividade de aquênios (Tabela 2), sendo, entre os fatores ambientais, a irregularidade e a diferença de precipitação pluviométrica o fator chave (Figura 1), pois a produtividade da cultura está diretamente relacionada com a disponibilidade de água. Em termos relativos, a perda de produtividade na FEVC, em Pentecoste, em comparação a AEDF, em Fortaleza, foi de 53,67\%. Avaliando a produtividade de girassol da variedade Sanbro, Demir et al. (2006), obtiveram os maiores rendimento com o aumento da frequência da irrigação e os menores rendimentos quando as plantas foram expostas a déficit hídrico. Avaliando lâminas de irrigação Silva et al. (2011) também observaram aumento na produtividade de aquênios de girassol das variedades Catissol e Embrapa 122 com o aumento da disponibilidade hídrica, no município de Pentecoste-CE.

A tolerância à falta de água depende da espécie e dentro de uma mesma espécie da variedade e do estádio de desenvolvimento da planta. Amorim et al. (2008), estudando genótipos de girassol destacou a variedade Embrapa 122 e o híbrido V20044 como sendo de maiores níveis de tolerância à seca. Dessa forma, a semeadura em épocas que proporcionem melhor aproveitamento das condições climáticas favoráveis deve ser pretendida. Backes et al. (2008), obtiveram uma redução na produtividade de 1.190 para $460 \mathrm{~kg} \mathrm{ha}^{-1}$ com o genótipo de girassol Embrapa 122 quando a semeadura passou apenas do final de janeiro para o início de fevereiro de 2007 no município de Papanduva-SC. Broch et al. (2009), também obtiveram variações na produtividade dessa variedade quando cultivada em diferentes municípios de Mato Grosso do Sul, chegando a ordem de $61,44 \%$.

Quanto ao arranjo das plantas, Braz e Rossetto (2010), não obtiveram diferenças na produtividade de girassol cultivadas nas populações de 45.000 e 75.000 plantas ha-1, produzindo, em média, $1.260 \mathrm{~kg} \mathrm{ha}^{-1}$. Dessa forma, a plasticidade quanto à resposta à variação no arranjo espacial depende da espécie e da variedade. Entre as culturas que apresentam elevada plasticidade fenotípica destaca-se a soja que altera seus componentes de produção em função do espaço disponível, porém, não afeta a produtividade (HEIFFIG et al., 2006; MAUAD et al., 2010).

\section{CONCLUSÕES}

1. Os fatores espaçamento entre linhas, densidade de plantio e local de cultivo não interagem simultaneamente sobre as características vegetativas das plantas e a produtividade de aquênios de girassol da variedade Embrapa 122;

2. A redução do espaçamento entre linhas ou o aumento da densidade de plantio afetam negativamente o comportamento vegetativo das plantas de girassol, exceto o índice de área foliar que aumenta com densidade de plantio;

3. No manejo espacial da cultura, o espaçamento entre linhas pode afetar a produtividade de aquênios de girassol da variedade Embrapa 122 dependendo do local de cultivo;

4. O local de cultivo é determinante no comportamento vegetativo e produtivo de aquênios de girassol da variedade Embrapa 122. 


\section{AGRADECIMENTOS}

À PETROBRAS (Petróleo Brasileiro S.A.) pelo o apoio financeiro.

\section{REFERÊNCIAS}

AFFÉRRI, F. S. et al. Avaliação de cultivares de girassol, em diferentes épocas de semeadura, no Sul do estado do Tocantins, safra 2005/2006. Ciência \& Desenvolvimento, v. 4 , n. 7, p. 79-87, 2008.

AMORIM, E. P. et al. Correlações e análise de trilha em girassol. Bragantia, v. 67, n. 2, p. 307-316, 2008.

AQUINO, L. A. de et al. Estimativa da área foliar do girassol por método não destrutivo. Bragantia, v. 70 , n. 4, p. 832836, 2011.

ARNABLI, R. F.; GUIMARÃES, D. P.; FARIAS NETO, A. L. de. Análise de crescimento de girassol em Latossolo com diferentes níveis de saturação por bases no Cerrado. Pesquisa Agropecuária Brasileira, v. 38, n. 2, p. 219-224, 2003.

ASHLEY, D. A.; DOSS, B. D.; VENNETT, O. L. A method of determining leaf area in cotton. Agronomy Journal, v. 55, n. 6, p. 584-585, 1963.

BACKES, R. L. et al. Desempenho de cultivares de girassol em duas épocas de plantio de safrinha no planalto norte Catarinense. Scientia Agraria, v. 9, n. 1, p. 41-48, 2008.

BRAZ, M. R. S.; ROSSETTO, C. A. V. Acúmulo de nutrientes e rendimento de óleo em plantas de girassol influenciados pelo vigor dos aquênios e pela densidade de semeadura. Semina: Ciências Agrárias, v. 31, suplemento 1, p. 11931204, 2010.

BRAZ, M. R. S; ROSSETTO, C. A. V. Crescimento de plantas de girassol em função do vigor de aquênios e da densidade de semeadura. Ciência Rural, v. 39, n. 7, p. 19891996, 2009b.

BRAZ, M. R. S; ROSSETTO, C. A. V. Estabelecimento de plântulas e desempenho de plantas em resposta ao vigor dos aquênios de girassol. Ciência Rural, v. 39, n. 7, p. $1997-$ 2003, 2009a.

BROCH, D. L. et al. Culturas oleaginosas de outono/inverno e integração lavoura/pecuária como alternativas para região Sul de Mato Grosso do Sul. In: Tecnologia e produção: soja e milho 2008/2009. Maracaju: Fundação MS, 2009, cap. 18, p. 183-200. Disponível em: <http://www.diadecampo.com.br> Acessado: 15 de dezembro de 2012.

CONAB. Acompanhamento da safra brasileira: grãos, quarto levantamento, janeiro de 2013. CONAB - Companhia nacional de Abastecimento, Brasília, 2013, 28 p.

DEMIR, A. O. et al. Deficit irrigation of sunflower (Helianthus annuus L.) in a sub-humid climate. Irrigation Science, v. 24, n. 4, p. 279-289, 2006.
EMBRAPA. Centro Nacional de Pesquisa de Solos. Sistema brasileiro de classificação de solos. 2 ed. Brasília: Empresa Brasileira de Pesquisa Agropecuária (EMBRAPA), 2006. $367 \mathrm{p}$.

HEIFFIG, L. S. et al. Fechamento e índice de área foliar da cultura da soja em diferentes arranjos espaciais. Bragantia, v. 65 , n. 2 , p. $285-295,2006$.

LARCHER, W. Ecofisiologia Vegetal. São Carlos: RIMA, 2006. 550 p.

LEITE, R. M. V. B. de C. et al. Indicações para o cultivo de girassol nos Estados do Rio Grande do Sul, Paraná, MatoGrosso do Sul, Mato Grosso, Goiás e Roraima. Embrapa-CNPSo, Londrina, 2007. 4 p. (Comunicado Técnico, 78).

MAPA. Anuário estatístico da agroenergia. 2 ed. 2011. MAPA - Ministério da Agricultura, Pecuária e Abastecimento, Brasília, 2011. 224 p.

MARTIN, T. N. et al. Spatial distribution of sunflower cultivars and the relationship between growth features. Revista Ciência Agronômica, v. 43, n. 2, p. 338-345, 2012.

MAUAD, M. et al. Influência da densidade de semeadura sobre características agronômicas na cultura da soja. Revista Agrarian, v. 3, n. 9, p. 175-181, 2010.

PIVETTA, L. G. et al. Avaliação de híbridos de girassol e relação entre parâmetros produtivos e qualitativos. Revista Ciência Agronômica, v. 43, n. 3, p. 561-568, 2012.

PORTO, W. S.; CARVAlHO, C. G. P.; PINTO, R. J. B. Adaptabilidade e estabilidade como critérios para seleção de genótipos de girassol. Pesquisa Agropecuária Brasileira, v. 42, p. 491 - 499. 2007.

RIBEIRO, J. L. Manejo da cultura do girassol no MeioNorte do Brasil. Embrapa Meio-Norte, Teresina, 2008. 9 p. (Circular Técnica, 48).

SILVA, A. R. A. da et al. Desempenho de cultivares de girassol sob diferentes lâminas de irrigação no Vale do Curu, CE. Revista Ciência Agronômica, v. 42, n. 1, p. 57-64, 2011.

SILVA, P. R. F. da; NEPOMUCENO, A. L. Efeito do arranjo de plantas no rendimento de grãos, componentes do rendimento, teor de óleo e no controle de plantas daninhas em girassol. Pesquisa Agropecuária Brasileira, v. 26, n. 9, p. 1503-1508, 1991.

TAIZ, L.; ZEIGER, E. Fisiologia Vegetal. 4. ed. Porto Alegre: ARTMED, 2009. 848 p.

YOKOMIZO, E. O combustível do girassol. CREA, Curitiba, n. 21, p. 18-23, 2003.

ZAFFARONI, E.; SILVA, M. A. V.; AZEVEDO, P. V. de. Potencial agroclimático da cultura do girassol no estado da Paraíba: II necessidade de água. Pesquisa Agropecuária Brasileira, v. 29, n. 10, p. 1493-1501, 1994. 